\title{
Hygienic Practice of Complementary Food Preparation and Associated Factors among Mothers with Children Aged from 6 to 24 Months in Rural Kebeles of Harari Region, Ethiopia
}

\author{
Desta Dugassa Fufa ${ }^{1{ }^{1 *}, \text { Aklilu Abhram }}{ }^{2}$, Awgichew Teshome ${ }^{3}$, Kedir Teji ${ }^{2}$, Fistum Abera ${ }^{4}$, \\ MaledaTefera $^{2}$, Meron Yeshitila ${ }^{2}$, Melese Mengistu ${ }^{4}$, Muluken Gezahegn ${ }^{5}$, Tadesse Gure ${ }^{6}$, \\ Teshager Worku ${ }^{2}$, Tadesse Alemayehu ${ }^{3}$, Gudina Egata ${ }^{7}$ \\ ${ }^{1}$ Department of Food Science and Postharvest Technology, Haramaya Institute of Technology, Haramaya University, Ethiopia \\ ${ }^{2}$ School of Nursing and Midwife, College of Health and Medical Sciences, Ethiopia \\ ${ }^{3}$ Department of Environmental Health, College of Health and Medical Sciences, Ethiopia \\ ${ }^{4}$ School of Plant Sciences, College of Agriculture and Environmental Sciences, Ethiopia \\ ${ }^{5}$ School of Rural Development and Extension, College of Agriculture and Environmental Sciences, Ethiopia \\ ${ }^{6}$ School of Medicines, College of Health and Medical Sciences, Ethiopia \\ ${ }^{7}$ School of Public Health, College of Health and Medical Sciences, Haramaya University, Ethiopia
}

Received March 14, 2020; Revised March 28, 2020; Accepted April 29, 2020

Copyright $(2020$ by authors, all rights reserved. Authors agree that this article remains permanently open access under the terms of the Creative Commons Attribution License 4.0 International License

\begin{abstract}
Introduction: Evidence shows that 10 to $20 \%$ of food-borne outbreaks perceptible in developing countries. The objective of this study was to assess the magnitude of hygienic practice of complementary food preparation and associated factors among mothers with children aged from 6 to 24 months in rural kebeles of Harari region, Ethiopia. The Method is a community based cross-sectional study design which was implemented on 422 of sampled mothers. Simple random sampling method was used to select those study participants. The data was collected using pre-tested and structured questionnaires. Data was processed, coded and entered into epi data version 3.02, exported to SPSS Version 20 and analyzed. Odds ratio along with $95 \%$ CI was estimated to measure the strength of the association. Finally, level of statistically significant was declared at $\mathrm{P}$-value $<0.05$. From the result of this study, the status of good hygienic practice of mothers was (39.6\%) [95\% CI (confidence interval): 34.60 , 43.90]. Lack of formal education [AOR (adjusted odds ratio): $[\mathrm{AOR}=0.177,95 \% \mathrm{CI}:(0.044,0.75)]$, learning grade $1-8$ [AOR $=0.214,95 \% \mathrm{CI}:(0.052,0.872)]$, age group of $25-30$ years $[\mathrm{AOR}=6.51,95 \% \mathrm{CI}:(1.38,30.50)]$, income $\geq$ 1000 ETB $[\mathrm{AOR}=2.19,95 \%$ CI: $(1.354,3.55)]$ and the presence of separate kitchen [AOR $=0.594,95 \%$ CI: $(0.390$, $0.906)]$ were significantly associated with complementary food preparation practice. The prevalence of good hygienic practice of complementary food preparation among of
\end{abstract}

mothers was low in this study. Hence, the concerned stakeholders in collaboration with Harar health bureau need to facilitate awareness raising activities on hygiene practice which help to prevent food borne.

Keywords Hygienic Practice, Complementary Food, Harari Region

\section{Introduction}

All conditions and measures necessary to ensure that food is safe and wholesome for human consumption is food hygiene. However, improper way of preparation and maintained in sanitary and safe condition is doubtful and causes diseases. In addition to these, poor food hygienic practice of complementary may account for a substantial section of diarrheal diseases. Then, food safety is a major causes young children in developing countries, which in turn, account for a large proportion of the global burden of infectious disease (Flint et al., 2005).

The availability of safe food is a basic human right that subsequently improves the health of people when consumed. People are becoming increasingly concerned about the health risks posed by microbial pathogens and potentially hazardous chemicals in food especially those 
that may enter food during preparation or when serving. The trends in global food production, preparation, processing, and distribution present new challenges to food safety (WHO, 2002).

A lot of world's especially poorest community die from preventable diseases each year which resulted from lack of good food hygiene. This problem of food borne disease is more serious about those mothers with children aged from 6 to 24 months in the rural communities because of their low level of awareness, susceptible, they are at a great risk of acquiring infections and poor food handling and unhygienic environment (Tadesse, 2015). Proper parental practices regarding the management, preparation, administration and storage of complementary foods may reduce their contamination (Temple et al., 2016).

Globally, more than $50 \%$ of the total food poisoning cases were attributed to improper food handling procedure. Around 600 million food borne illnesses and 420,000 deaths occur each year due to poor food handling practice. Among ten people, one becomes ill from ingestion of contaminated food (Lee et al., 2017). The transmission of food-borne diseases is aggravated by unsafe food handling practices of mothers. Approximately 10 to $20 \%$ of food-borne diseases in outbreaks are because of uncleanness by mother's food preparation practice (Mudey et al., 2010).

Since studies conducted in some parts of Ethiopia (Gizaw et al., 2014), regarding hygienic practice complementary food preparation showed that the existing practice was prone to cause food borne diseases. Therefore, those findings need to be further strengthened by conducting other studies in areas where not previously considered. In rural kebeles of Harari Region, Ethiopia there are less data was documented on hygienic practice of complementary food preparation and associated factors among mothers with children aged from 6 to 24 months that showed in the local context.

Therefore, the purpose of this study will be to assess the status hygienic practice of complementary food preparation and associated factors among mothers with children aged from 6 to 24 months in selected rural kebeles. Then, improvements are needed to better identify the causes of complementary food preparation practices and associated factors in rural kebeles of Harari Region.

The result of this research may be used by researchers, academia, non-governmental organizations and other program implementers. And also, may help to develop guidelines for local setting practices, baseline for program planners and intervention purpose who are interested in working food hygiene program as to improve the quality of food hygiene in the region. In addition, students and (or) scholars could use it as reference to their work in the future.

\subsection{Objectives}

\subsubsection{General Objective}

To assess hygienic practice of complementary food preparation and associated factors among mothers with children aged from 6 to 24 months in rural kebeles of Harari region, Ethiopia

\subsubsection{Specific Objectives}

- $\quad$ To determine the prevalence of hygienic practice of complementary food preparation

- To identify factors associated with hygienic practice of complementary food preparation

\section{Methods}

\subsection{Study Area and Period}

This research study was conducted as part of a larger Haramaya University (HU) grant from thematic research project of fiscal academic year 2017/2018 method entitled under 'First 1000 Days Nutrition Intervention in Rural Kebeles of Harari Region, Eastern Ethiopia: A Randomized Control Trial'

The Administrative center of Harari region is Harar, which is located at $525 \mathrm{~km}$ far from Addis Ababa capital city of Ethiopia. Harari region is one the nine regional states of Ethiopia which is bordered on the North by Kombolcha and Jarso woreda, on the South by Fedis woreda, on the East by Gursum and Babile woreda, on the west by Haramaya district. There are 7 hospitals, 8 health centers and 32 health posts. Harari region is administratively structured into 36 (19 urban and 17 rural) kebeles. According to the regional health office report (2009) there were 63,068 (40,904 urban and 22,164 rural) households with a total population of 245,969 from this 120,524 of them are male and 125,444 are female (CSA, 2009). The study was conducted, from April 2019 to May $30,2019$.

\subsection{Study Design}

A community- based cross-sectional study design was carried out.

\subsubsection{Population}

\subsubsection{Source Population}

The source populations of the study were all mothers who have children aged from 6 to 24 months and are found in rural kebeles of Harar region, Ethiopia. 


\subsubsection{Study Population}

All mothers were who have children aged from 6 to 24 months randomly selected kebeles during the study period.

\subsection{Inclusion and Exclusion Criteria}

\subsubsection{Inclusion Criteria}

All mothers who have children aged from 6 to 24 months were included in the study.

\subsubsection{Exclusion Criteria}

Mothers who were unable to respond, and seriously health problem during the data collection period were excluded from the study.

\subsection{Sample Size Determination}

Sample size was estimated using a single population proportion formula by considering $52.1 \%$ had good food hygiene practice (Brahay 2018), 5\% margins of error at $95 \%$ confidence levels and adding 10\% non-response rate. Based on this assumption, the actual sample size for the study was determined using a single population proportion formula. Considering an estimated non-response $10 \%$, added to the calculated sample size giving 422 samples.

Therefore, a total of 422 mothers were selected for the first objective and included in this study.

\subsection{Sampling Methods and Procedure}

In this study, two stages sampling procedure were employed to draw samples of the study. First, eight kebeles were selected by lottery method from a total of 17 rural kebeles of Harari region. Next, mothers with children aged from 6 to 24 months were selected using proportional allocation to sample size from each kebeles. Similarly, those mothers having children aged from 6 to 24 months in the same house living were selected by lottery methods. Finally, the sample size required for the study was randomly selected from the eight kebeles. All households from selected kebeles with mothers have children aged from 6 to 24 months was included whereas those mothers have more than two children were excluded during the study period.

\subsection{Study Variables}

\subsubsection{Dependent Variable}

Status of complementary food preparation practice (good and poor)

\subsubsection{Independent Variables}

- $\quad$ Socio-demographic factors

- Educational status

- Occupation

- Age
- Sex
- Family size
- Income status in birr
- Training

\subsection{Data Collection Procedure}

\subsubsection{Data Collectors and Data Collection Procedures}

Pre-test and structure interviewer administered questionnaires were used during the data collection. Data on independent variables were collected by using structured pretested Afan Oromo and English version questionnaires (CSA, 2011; Usman et al., 2016). Three grades 10 completed students were recruited as data collectors and trained for two days. And two B.Sc. holders in Environmental Health were also recruited and trained for supervising data collectors. Training was given to hygienic practice of complementary food preparation and associated factors among mothers with children aged from 6 to 24 months, interviewing technique and filling questionnaires, and how to approach respondents including respecting ethical.

\subsection{Data Quality Control}

The original version of the tools is written in English; yet, since the tools are planned to be administered to study participants in their native Afan Oromo language, questionnaires were translated to Afan Oromo then back-translated to English to ensure parallel-form consistency. Pre-test was conducted 5\% of households outside the selected kebeles before actual data collection.

\subsection{Data Processing and Analysis}

Data were processed, coded, entered into epi data version 3.02 computer software and exported to SPSS version 20 computer software cleaned and analyzed. Descriptive statistics were run to check for any missing values. Summary of descriptive statistics such as frequencies, percent, means, and standard deviation (SD) were used to describe socio demographic characteristics. Tables and figure were prepared for reporting in frequency of socio demographic characteristics and status of hygienic practice respectively.

Finally, hygienic practice of complementary food preparation was assessed based on related seven questions which contain three-point score scale was used for analysis of response (always, sometimes and never). The practice level score of six and below marks out of maximum was considered as poor practice whereas a score seven and above was graded as good practice.

During bi-variable analysis, crude odds ratio along with 
$95 \%$ of C.I was used to see the association with each independent variable and the outcome variable by using binary logistic regression model. Independent variables with p-value of $\leq 0.2$ were included in a multi-variable analysis to control for all possible confounding and identify factors associated with the hygiene practice. Then outliers and influential cases were checked by standardized residuals and cook's distance respectively. Cases of standardized residuals out of the interval $(-3,3)$ and cook's distance above 1 were excluded from the multivariable analysis. Multi-collinearity was also checked to see the linear correlation between the independent variables by using a standard error and variance inflation factor. Variables with the standard error of $>2$ and the variance inflation factor (VIF) from one to ten were dropped from the multivariable analysis. Hosmer Lemeshow goodness of fit tests was used to check for model fitness by looking cut of point $>0.05$ and the used was forwarded. The continuous variables such as age were tested using the normal curve with a histogram. An adjusted odds ratio along with $95 \%$ confidence intervals was estimated to measure the strength of association with dependent and independent variable. In this study level of statistical significance was declared at $\mathrm{P}$-value $<0.05$.

\subsection{Ethical Considerations}

Before starting the data collection process, Haramaya University the College of Health Medical Sciences Institutional Health Research Ethics Review Committee (IHRERC) has approved the protocol ethical clearance was received from Thematic Research project: Thematic CodeHURG-2017-02-02-09 and the official letter were obtained from department of Environmental Health to Harari region Health Office. Informed voluntary written and signed consent was obtained from each participant after explaining the purpose and benefits of the study. The culture of the study participants' throughout the data collection process was respected. Confidentiality of the study participants' information also ensured.

\section{Results}

All 422 were participated in a $100 \%$ response rate. The results mainly fall into two categories: status of complementary food preparation practice and associated factors.

\subsection{Socio-demographic Characteristics of Study Participants}

The age range of all was 19-42 years. The mean and standard deviation $( \pm \mathrm{SD})$ age of participants was $27.1 \pm$ 3.6 years old. Most of the participants, 286(67.8\%) lie in the age group between 25-30 years. Two hundred seventy-three $(64.7 \%)$ respondents have less or equal to five family sizes with mean of $5.2 \pm(1.9 \mathrm{SD})$. And 393 (93.1\%) of respondents (mothers) were Muslim in religion. Oromo 326(77.3\%) was the largest ethnic group. Concerning the educational status of the study participant, above half 224(53.1\%) of respondent had been unable to read and write (no formal education). Three-hundred seventy-one $(87.9 \%)$ of participants were married. Looking the occupational of participants $312(73.9 \%)$ were farmers. Out of the total respondents, $78 \%$ earned an average monthly income of less than or equal to 999 Ethiopian Birr (ETB). In case of hygiene practice training, 335(79.4\%) of study participants were not attended food hygiene practice training (Table 1).

Table1. Socio-demographic characteristics of study participants in Harari Region, $2019(\mathrm{n}=422)$

\begin{tabular}{|c|c|c|c|}
\hline Variables & Categories & Frequency & $\begin{array}{l}\text { Percentage } \\
(\%)\end{array}$ \\
\hline \multirow{2}{*}{$\begin{array}{l}\text { Heads of } \\
\text { households }\end{array}$} & Male & 310 & 73.5 \\
\hline & Female & 112 & 26.5 \\
\hline \multirow{4}{*}{ Mothers' age } & $19-24$ & 81 & 19.2 \\
\hline & $25-30$ & 286 & 67.8 \\
\hline & $31-36$ & 47 & 11.1 \\
\hline & $37-42$ & 8 & 1.9 \\
\hline \multirow{4}{*}{ Religions status } & Muslim & 393 & 93.1 \\
\hline & Orthodox & 23 & 5.5 \\
\hline & Protestant & 4 & 0.9 \\
\hline & Others* & 2 & 0.5 \\
\hline \multirow{4}{*}{$\begin{array}{l}\text { Mothers' } \\
\text { educational status }\end{array}$} & $\begin{array}{l}\text { No formal } \\
\text { education }\end{array}$ & 225 & 53.3 \\
\hline & Grade 1-8 & 114 & 27.1 \\
\hline & Grade 9-12 & 71 & 16.8 \\
\hline & $\begin{array}{l}\text { College and } \\
\text { above }\end{array}$ & 12 & 2.8 \\
\hline \multirow{4}{*}{ Ethnicity } & Oromo & 326 & 77.3 \\
\hline & Amhara & 58 & 13.7 \\
\hline & Harari & 32 & 7.6 \\
\hline & Others $* *$ & 6 & 1.4 \\
\hline \multirow{3}{*}{$\begin{array}{l}\text { Current marital } \\
\text { status }\end{array}$} & Married & 371 & 87.9 \\
\hline & Divorced & 41 & 9.7 \\
\hline & Widowed & 10 & 2.4 \\
\hline \multirow{5}{*}{$\begin{array}{l}\text { Mothers' } \\
\text { occupational } \\
\text { status }\end{array}$} & Petty trading & 65 & 15.4 \\
\hline & Employment & 6 & 1.4 \\
\hline & Farmer & 312 & 73.9 \\
\hline & Housewife & 35 & 8.3 \\
\hline & Others $* * *$ & 4 & 0.9 \\
\hline \multirow{2}{*}{ Family size } & $\leq 5$ & 273 & 64.7 \\
\hline & $>5$ & 149 & 35.3 \\
\hline \multirow{2}{*}{$\begin{array}{l}\text { Income status } \\
\text { (ETB) }\end{array}$} & $\leq 999$ & 329 & 78.0 \\
\hline & $\geq 1000$ & 93 & 22.0 \\
\hline \multirow{2}{*}{$\begin{array}{l}\text { Food hygiene } \\
\text { practice training }\end{array}$} & Yes & 87 & 20.6 \\
\hline & No & 335 & 79.4 \\
\hline
\end{tabular}

Note: *- Catholic, ** - Somali, and ***- Daily labor respectively 


\subsection{Hygiene Practice of Complementary Food Preparation among Mothers}

Hygiene practice of complementary food preparation mothers was assessed based on related questions. Each question has three options (always, sometimes, and never).
The mean score value and standard deviation $( \pm \mathrm{SD})$ of complementary food preparation practice of mothers was 6.4 \pm 1.8. The magnitude of good complementary food preparation practice was found to be $167(39.6 \%)$ of the study participants (mothers) (Figure 1).

Status of hygienic practice of complementary food preparation

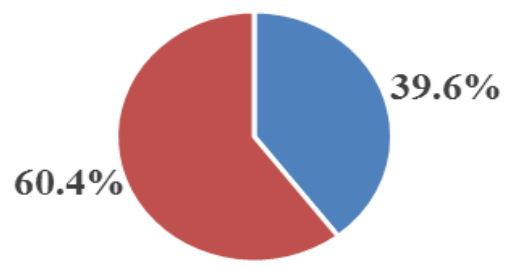

- Good practice

- Poor practice

Figure 1. Overall the magnitude of good complementary food preparation practice among mothers with children aged from 6 to 24 months in rural kebeles of Harar Region, Ethiopia, 2019

Table 2. Complementary food preparation practice among mothers $(\mathrm{n}=422)$

\begin{tabular}{|c|c|c|c|c|}
\hline \multirow{2}{*}{ Variables } & \multirow{2}{*}{ Categorical } & \multicolumn{2}{|c|}{ Level of hygienic practice (\%) } & \multirow{2}{*}{$\begin{array}{l}\text { Number } \quad \text { of } \\
\text { respondents }\end{array}$} \\
\hline & & Good & Poor & \\
\hline \multirow{3}{*}{ Handwashing with soap and water before food preparation } & Always & $3(18.8)$ & $13(81.2)$ & $16(3.8)$ \\
\hline & Sometimes & $33(39.3)$ & $51(60.7)$ & $84(19.9)$ \\
\hline & Never & 131(40.7) & 191(59.3) & $322(76.3)$ \\
\hline \multirow{3}{*}{ Handwashing with soap and water after visiting toilet } & Always & $8(33.3)$ & $16(66.7)$ & $24(5.7)$ \\
\hline & Sometimes & $25(38.5)$ & $40(61.5$ & $65(15.4)$ \\
\hline & Never & $134(40.1)$ & 199(59.9) & $333(78.9)$ \\
\hline \multirow{3}{*}{ Children handwashing before eating food } & Always & $24(31.2)$ & $53(68.8)$ & $77(18.2)$ \\
\hline & Sometimes & $95(40.4)$ & $140(59.6)$ & $235(55.7)$ \\
\hline & Never & $48(43.5)$ & $62(56.4)$ & $110(26.1)$ \\
\hline \multirow{3}{*}{ Handwashing after cleaning children stool } & Always & $23(28)$ & $59(72)$ & $82(19.4)$ \\
\hline & Sometimes & $58(47.2)$ & $65(52.8)$ & $123(29.1)$ \\
\hline & Never & $86(39.6)$ & $131(60.4)$ & 217(51.4) \\
\hline \multirow{3}{*}{ Cleaning and trimming fingernails } & Always & $81(37.2)$ & $137(62.8)$ & $218(51.7)$ \\
\hline & Sometimes & $55(45.5)$ & $66(54.5)$ & $121(28.7)$ \\
\hline & Never & $31(37.3)$ & $52(62.7)$ & $83(19.7)$ \\
\hline \multirow{3}{*}{$\begin{array}{l}\text { Washing raw vegetables and fruits with running water before } \\
\text { eating }\end{array}$} & Always & $135(43.5)$ & $175(56.5)$ & $310(73.5)$ \\
\hline & Sometimes & $26(27.4)$ & $69(72.6)$ & $95(22.5)$ \\
\hline & Never & $6(35.3)$ & 11(64.7) & $17(4.1)$ \\
\hline \multirow{3}{*}{ Cleaning food preparing equipment and tools before use } & Always & $77(34.8)$ & $144(65.2)$ & $221(52.4)$ \\
\hline & Sometimes & $31(43.1)$ & $41(56.9)$ & $72(17.1)$ \\
\hline & Never & $59(45.7)$ & $70(54.3)$ & $129(30.6)$ \\
\hline
\end{tabular}


Among mothers assessed, 322(76.3\%) of them never wash their hands with soap and water before food preparation. Likewise, three-fourth $333(78.9 \%$ ) of the mothers never wash their hands with soap and water after visiting the toilet. Three-hundreds and ten (73.5\%) of the mothers always wash raw vegetables and fruits with running water before eating. In other way, two hundred and twenty one $(52.4 \%)$ of the respondents always clean equipment/ (utensils) and tools before they are used for food preparing. Thus, $77(34.8 \%)$ of them practiced good complementary food preparation practice of cleaning equipment (utensils) and tools (Table 2).

\subsection{Complementary Food Preparation Practices of Food Serving among Mothers}

Out of the total sampled mothers, 386(91.5\%) of them practiced hand washing before feeding their child. Three -hundred ninety- two $(92.8 \%)$ mothers served food to their children immediately after preparation. Three hundred fifty-six (85.5\%) participants(mothers) responded that they are keeping cooked and raw food separately. All mothers used cleaned cup and bowls when during feeding their children. Two- third 258(61.2\%) of mothers have separate kitchen facility for food preparation. Four hundred seven (96.4\%) of mothers were covering food after cooking. Only $12(2.8 \%)$ of the household had a separated place for their cattle

The latrine and hand washing facility of household had $412(97.8 \%)$ and 416(98.6\%) respectively. Three-fourth $336(79.6 \%)$ of mothers was no solid disposal pit. And $405(97.9 \%)$ of mothers did not use left-over food to serve for their children (Table 3 ).

\subsection{Associated Factors with Complementary Food Preparation Practice}

Logistic regression model was used to identify the status of associated factors of hygienic practice. Table 4 showed that the bi-variable and multivariable logistic regression analysis of factors associated with complementary food preparation practice among mothers. Age group of 25-30 years $[\mathrm{COR}=6.28,95 \%$ CI:(1.36,28.92)], no formal education and grade 1-8 education with $[\mathrm{COR}=6.01,95 \% \mathrm{CI}:(6.01,22.82) \quad$ and $\mathrm{COR}=4.95,95 \% \mathrm{CI}: 1.27,19.31)]$, respectively were found to be associated with hygienic practice. The family size having less than or equal to five crude odd ratios [COR $=1.57,95 \% \mathrm{CI}:(1.045,2.356]$, average monthly income those who have greater than or equal to $1000 \mathrm{ETB}$ odd ratio with $[\mathrm{COR}=2.11,95 \%$ C.I: $(1.32,3.36)]$, hygiene practice training with $[\mathrm{COR}=0.567,95 \% \mathrm{CI}:(0.352,0.912)]$, and separate kitchen facility $[\mathrm{COR}=1.52,95 \% \mathrm{CI}$ : $(1.021,2.266)]$ were also statistically significant $(\mathrm{P}<0.05)$ factors associated with hygienic practice of complementary food preparation.

In the multivariable logistic regression analysis is being in the age group of 25-30 years, no formal education and grade 1-8 education and separate kitchen facility were significantly associated factors of complementary food preparation practice whereas other rest was showed that was no significantly associated factors.

Mothers with educational background of no formal education and grade 1-8 toward hygiene practice of complementary food preparation were $83 \%$ and $79 \%$ less likely to have good complementary food preparation practice respectively $[\mathrm{AOR}=0.177,95 \% \mathrm{CI}(0.044,0.75)]$ and $[\mathrm{AOR}=0.214,95 \% \mathrm{CI}(0.052,0.872)]$ as compared to mothers with college and above. The result also showed mothers with age group 25-30 were six times more likely $[\mathrm{AOR}=6.51,95 \%$ CI $(1.38,30.50)]$ to have good complementary food preparation practice compared with those age group of 19-24 years old (Beruk et al., 2015.

Table 3. Complementary food preparation practices of food serving children among mothers with children aged from 6 to 24 months in rural kebeles of Harari Region, Ethiopia,2019(n=422)

\begin{tabular}{|c|c|c|}
\hline \multirow{2}{*}{ Variables } & \multicolumn{2}{|c|}{ Number of respondents $(n=422)$} \\
\hline & Yes & No \\
\hline Handwashing before feeding children & $386(91.5)$ & $36(8.6)$ \\
\hline Food serving immediately after preparation & $392(92.8)$ & $30(7.1)$ \\
\hline Using clean cups and bowls when feeding children & $422(100)$ & 0 \\
\hline Separate kitchen facility & $258(61.2)$ & $164(38.9)$ \\
\hline Using clean utensils during preparation of food & $310(73.5)$ & $112(26.5$ \\
\hline Latrine availability & $10(2.4)$ & $412(97.8)$ \\
\hline Handwashing facility & $6(1.4)$ & $416(98.6)$ \\
\hline Solid disposal pit availability & $86(20.4)$ & $336(79.6)$ \\
\hline Keeping cooked and raw foods separately & $361(85.5)$ & $61(14.5)$ \\
\hline Separate cattle living room & $12(2.8)$ & $410(97.2)$ \\
\hline Covering cooked food & $407(96.4)$ & $15(3.6)$ \\
\hline Children using leftover food & $17(4.1)$ & 405(97.9) \\
\hline
\end{tabular}


Hygienic Practice of Complementary Food Preparation and Associated Factors

among Mothers with Children Aged from 6 to 24 Months in Rural Kebeles of Harari Region, Ethiopia

Table 4. Bivariate and multivariable logistic regression analysis of associated factors with complementary food preparation practice among mothers

\begin{tabular}{|c|c|c|c|c|c|c|c|}
\hline \multirow{2}{*}{ Variables } & \multirow{2}{*}{ Categories } & \multicolumn{2}{|c|}{ Level of hygiene practice } & \multirow[t]{2}{*}{ COR $(95 \%$ C.I) } & \multirow[t]{2}{*}{ P-Value } & \multirow[t]{2}{*}{ AOR (95\% C.I) } & \multirow[t]{2}{*}{ P-Value } \\
\hline & & Good (\%) & Poor $(\%)$ & & & & \\
\hline \multirow{4}{*}{ Mothers' age } & $19-24$ & $17(10.2)$ & $64(25.1)$ & 1 & & 1 & \\
\hline & $25-30$ & $117(70.1)$ & $169(66.3)$ & $2.606(0.61,2.012) *$ & 0.008 & $2.45(1.405,3.015) *$ & 0.017 \\
\hline & $31-36$ & $28(16.8)$ & $19(7.5)$ & $2.129(0.56,1.39)$ & 0.139 & $2.373(0.55,10.35)$ & 0.249 \\
\hline & $37-42$ & $5(3)$ & $3(1.2)$ & $1.131(0.24,5.31)$ & 0.627 & $1.139(0.238,5.44)$ & 0.87 \\
\hline \multirow{4}{*}{$\begin{array}{l}\text { Mothers educational } \\
\text { status }\end{array}$} & No formal education & $75(44.9)$ & $150(58.8)$ & $0.166(0.28,0.72) *$ & 0.009 & $0.203(0.051,0.818) *$ & 0.025 \\
\hline & Grade 1-8 & $43(25.7)$ & $71(27.8)$ & $1.211(0.38,1.131) *$ & 0.02 & $1.14(0.052,0.872) *$ & 0.032 \\
\hline & Grade $9-12$ & $40(24)$ & $31(12.2)$ & $2.133(0.58,9.32)$ & 0.234 & $0.53(0.126,2.233)$ & 0.387 \\
\hline & College and above & $9(5.4)$ & $3(1.2)$ & 1 & & 1 & \\
\hline \multirow{2}{*}{ Family size } & $\leq 5$ & $98(58.7)$ & $175(68.6)$ & $0.649(0.045,0.356) *$ & 0.03 & $0.687(0.450,1.049)$ & 0.082 \\
\hline & $>5$ & $69(41.3)$ & $80(31.4)$ & 1 & & 1 & \\
\hline \multirow{2}{*}{ Income status (ETB) } & $\leq 999$ & $117(70.1)$ & $212(83.1)$ & 1 & & & \\
\hline & $\geq 1000$ & $50(29.9)$ & $43(16.9)$ & $2.107(1.322,3.357) *$ & 0.002 & $2.19(1.354,3.55) *$ & 0.001 \\
\hline \multirow{2}{*}{ Hygiene practice training } & Yes & $44(26.3)$ & $43(16.9)$ & $1.763(0.363,0.936)$ * & 0.025 & $1.552(0.948,2.541)$ & 0.08 \\
\hline & No & $123(73.7)$ & $212(83.1)$ & 1 & & 1 & \\
\hline \multirow{2}{*}{ Hand washing facility } & Yes & $4(2.4)$ & $2(0.8)$ & $0.322(0.058,1.779)$ & 0.194 & $3.13(0.497,19.698)$ & 0.224 \\
\hline & No & $163(97.6)$ & $253(99.2)$ & 1 & & 1 & \\
\hline \multirow{2}{*}{ Separate kitchen facility } & Yes & $92(35.7)$ & $166(64.3)$ & $0.658(0.031,0.456) *$ & 0.04 & $0.594(0.390,0.906) *$ & 0.015 \\
\hline & No & $75(45.7)$ & $89(39.3)$ & 1 & & 1 & \\
\hline
\end{tabular}




\section{Discussion}

Based on this study, the status of good complementary food preparation practice among mothers was 39.6\%. Factors such as age, an education background, monthly income, hygiene practice training and separate kitchen facility were associated with hygiene practice on mother complementary food preparation of their children.

The current study showed that the magnitude of good complementary food preparation practice was $(39.6,95 \%$ CI: $(34.60 \%, 43.90 \%)$. The result is similar with the study conducted in Nigeria $36.50 \%$ (Iwu et al, 2017) and in Debark Northwest, Ethiopia 40.1\% (Fasikaw et al., 2019). The similarities may be due to socio demographic characteristics. This figure is prominently lower than the study conducted in Jordan (89.43\%) (Sharif et al, 2013), Malaysia (71.8\%) (Zain, and Naing.2013), Sri Lanka (60\%) (Galgamuwal et al., 2016), and Dangila, Ethiopia (52.5\%) (Ayehu et al.,2014). This may be due to awareness, and accesses difference in facility on complementary food preparation practice among mothers.

However, this study finding was higher than the study conducted in Thailand (15.2\%) (Cuprasitrut et al., 2011), in Gondar, Ethiopia which is $30.3 \%$ (Gizaw et al., 2014) and Somali (20.9\%) (Mohammed 2018). This difference may be due to socio demographic characteristics and the number of sample size variation.

The odds of performing good hygienic practice among mothers who are in the age group of 25-30 years were 6.51 times higher as compared to those who age group is 19-24 years. As significantly, findings were reported in south Ethiopia (Beruk et al.,2015). The possible reason may be developing good experience toward complementary preparation practice and feeding children when the age of mother is increasing.

Mothers whose monthly income is greater than or equal to 1000.00 ETB was 2.19 times more likely to have good hygiene practices $[\mathrm{AOR}=2.19,95 \% \mathrm{CI}, 1.354,3.55)]$ compared to those who had monthly income less than or equal to $999.00 \mathrm{ETB}$. In other studies, the mean income status of mothers was identified as a significant factor (Almedom, 2016). The possible reason for this might be those who have good income will have capacity to build their own resource construction of house, have safe source of drinking water and keeping their personal and environmental hygiene and so that these all helps them keep good complementary food preparation practice. Likewise, the odds of performing good complementary food preparation practice among mothers who attended the training on complementary food preparation practice were 1.54 times higher as compared to those who did not attend any trainings. This result was supported by (Thelwell, 2014). The reason behind could be the training raises their awareness and concern for food borne diseases. The other possible reason for this might be those who had been training might have good educational status, experience and knowledge towards complementary food preparation practices.

The odds of performing good hygiene practice among mothers who have an educational background no formal education and grade $1-8$ was $83 \%$ and $79 \%$ less than those mothers who have educational background college and above respectively. In other studies, educational status was identified as a significant factor, Debark, northwest Ethiopia (Fasikaw et al., 2019). The reason behind, may be education enables/s mothers to improve knowledge and awareness of the nature of work to be allotted at a given area.

But there might be a recall bias among the participants and the result finding may not be generalized. The limitation of this study was not supported by direct-observations during hygienic practice of complementary food preparation.

\section{Conclusions and Recommendations}

\subsection{Conclusions}

The magnitude of good hygiene practice complementary food preparation of mothers is low in this study, which is still prone to food borne illnesses and harms the health of under two years children. Moreover, improving hygiene practice of complementary food preparation among mothers can help to reduce health harm issues.

The identified factors are significantly associated with hygienic practice of complementary food preparation to mothers. Therefore, acting on those factors could have its own contribution on the improvement of food hygiene practice among mothers those have children aged from 6 to 24 months.

\subsection{Recommendations}

Based on the current result of this study, it can contribute a lot to policy makers and others related body. Based on this finding; therefore, the following points are recommended:

Further studies that explore the practice of hand washing with soap at critical times by caregiver (mother) and food hygiene practice of knowledge, and attitude toward hygienic complementary food preparation among mothers should be made. Analytical study design is recommended to establish a cause and affect the relationship between associated factors and hygienic practice complementary food preparation among mother should be made. Harari Region Health Office should create awareness and further development and testing of strategies for scaling up food hygiene practice and also favorable behavioral change in complementary food preparation practice of food handlers

\section{Acknowledgments}

First and above all, we praise God, the Almighty for bestowing His mercy, peace, protection, and stamina that 
brought and capability to proceed successfully. We would like to express our deepest acknowledged and extend great deal of thanks and gratitude to Haramaya University research Sub-Theme Human Health, Nutrition, and Welfare particularly under entitled "First 1000 Days Nutrition Intervention" project for providing fund to conduct this research throughout study period. We have got greatly valued support that from Harari region water supply and sewerage authority and Harari Region Health Bureau Administration who provided the necessary information in the study of rural kebeles of Harari region. And also acknowledge and grateful the backbone of this study to data collectors. Finally, we greatly indebted to all my friends, and staff members

\section{Conflict of Interest}

There is no conflict of interest of authors in this project.

\section{Contribution of Authors}

Authors' contribution comprehended and designed the experiments, wrote and develop the proposal and data was collected by Aklilu Abhram, Awgichew Teshome, Kedir Teji, Fistum Abera, Maleda Tefera, Meron Yeshitila, Melese Mengistu, Muluken Gezahegn, Tadesse Gure, Teshager Worku,. The data was analyzed and wrote up final report by Desta Dugassa. This paper was taken under guidance and appears like this by Tadesse Alemayehu, and Gudina Egata. All authors read and approved the final manuscript as well.

\section{REFERENCES}

[1] Almedom AM: 2016.Recent developments in hygiene behavior research: an emphasis on methods and meaning. Trop Med Int Health, 1(2):171-182

[2] Ayehu G. Tessema AG, Gelaye KA, and Chercos DH. 2014. Factors affecting food handling practices among food handlers of Dangila town food and drink establishments, North West Ethiopia. BMC Public Health.; 14(1):571.

[3] Beruk Berhanu, Kebede Abegaz, and Esayas Kinfe.2015. Assessment knowledge and practices on complementary food preparation and child feeding at Shebedino, Sidama Zone, Southern Ethiopia. International Journal of Food Science and Nutrition Engineering, 5(2): 82-87

[4] Brahay C.P. 2018. Magnitude of hygienic practices of food preparation and its associated factors among mothers working as volunteers in selected rural kebeles of Puttarh District, Northern Sudan. International food research journal, 22(6): 2650- 2656.

[5] Central Statistical Agency (CSA).2011. Ethiopia Demographic and Health Survey.
[6] Cuprasitrut.T Srisorrachatr S and Mali D. 2011. Food safety knowledge, attitude and practice of food handlers in Rachathewi, Bangkok, Asia. Journal of public health; 2:27-34

[7] Fasikaw Adbarie Chekol, Melkitu Fentie Melak, Aysheshim Kassahun Belew and Ejigu Gebeye Zeleke. 2019. Food handling practice and associated factors among food handlers in public food establishments, Northwest Ethiopia. BMC Research Notes, 12:20

[8] Flint JA, Van Duynhoven YT, Angulo FJ, and Delong, SM. 2005.Estimating the Burden of Acute Gastroenteritis, Foodborne Disease and Pathogens Commonly transmitted by food. An international review. Clin Infect Dis.;41: 698-704.

[9] Galgamuwal T, Iddawela, D, and Samath Dh. 2016. Knowledge and practices of food hygiene among food handlers in plantation sector, Sri Lanka. International Journal of Scientific Reports;2(12):304-311

[10] Gizaw Z, Gebrehiwot M, and Teka Z. 2014. Food safety practice and associated factors of food handlers working in substandard food establishments in Gondar Town, Northwest Ethiopia, Int J Food Sci Nutrition Diet ,3(7):138-46.

[11] Mudey, N B., Kesharwani, G. A., Mudey, R. C., Goyal, A. K. Dawale, and Wagh V. V. 2010. Health status and personal hygiene among mother working at home around a rural and teaching hospital in wardha district of maharashtra, India. Global Journal of Health Science, (2) 2:198-201.

[12] Tadesse D. 2015. Rapid assessment of drinking-water quality in the Federal Democratic Republic of Ethiopia: country report of the pilot project implementation, 35-39.

[13] Temple VJ, Badamosi EJ, Laeji O, and Solomon T. 2016. Proximate chemical composition of three locally formulated complementary foods. West African, Journal of Biological Science 5: 134-143.

[14] Thelwell, M.R. 2014. Food safety knowledge and self-reported practices of food handlers in Jamaica (doctoral dissertation), University of Walden. (Scholar Works), Minneapolis, Minnesota. U.S.A.

[15] Usman. M.A, Gerber. N and Pangaribowo. E.H .2016. Determinants of household drinking water quality in rural Ethiopia. Center for development research (ZEF), 6(1):345.

[16] WHO (World Health Organization). 2002. Global Strategy for Food Safety: Safer Food for Better Health. Geneva, Switzerland: World Health Organization; 101:15

[17] Zain M, and Naing N. 2013. Sociodemographic characteristics of food handlers and their knowledge, attitude and practice towards food sanitation: a preliminary report. Southeast Asian. J Trop Med Public Health. 33 (2): 410-417. 